\title{
Severe preeclampsia at the University Hospital Center of Mother and Child (UHCMC) in N'djamena: Epidemiology
} and prognosis

\author{
Foumsou $L^{1,2 *}$, Kouamé $A^{3}$, Danmadji $\mathrm{NL}^{2}$, Gabkika $\mathrm{BM}^{1,2}$, \\ Damthéou $\mathrm{S}^{1,2}$ and Aché $\mathrm{H}^{1,4}$
}

${ }^{1}$ Department of Gynecology and Obstetrics, Faculty of Human Health Sciences, University of N'Djamena, Chad

'University Hospital Center N'Djamena, Chad

${ }^{3}$ Department of Gynecology and Obstetrics, Felix Houphouet Boigny University, Abidjan, Ivory Coast ${ }^{4}$ National Fistula Treatment Centre, N'Djamena, Chad

\section{Abstract}

Introduction: Preeclampsia constitutes a public health problem in our region. According to the WHO, it is the third cause of maternal mortality after severe hemorrhages, infections and is responsible for morbidity and high fetal mortality. The aim of this study was to improve on the management of severe preeclampsia at the University Hospital Center of Mother and Child (UHCMC) in N'Djamena.

Patients and method: It was a prospective and descriptive survey of 3 years duration, from January $01^{\text {st }}, 2017$ to December $31^{\text {st }}, 2019$. Included in our study were, all patients admitted for severe preeclampsia and agreed to participate in the study. Epidemiological, clinical, therapeutic and prognostic studies were conducted. The data collected was analyzed using SPSS 18.0 software.

Results: During the study period, 13599 pregnant and parturients were admitted to the Gynecology-Obstetrics department of the UHCMC, among whom 406 cases of severe preeclampsia, with a frequency of $2.9 \%$. The patients were young (23.2 years), married $(96.3 \%)$, primipara $(61.3 \%)$, referred $(64.3 \%)$ without antenatal care in $47.9 \%$ of cases. Functional signs were dominated by headaches with $34.0 \%$ of cases. The proteinuria was $\geq 3$ crosses in $83.7 \%$ of cases. Patients had received magnesium sulfate in $98.3 \%$, the delivery mode was cesarean in $64.0 \%$ of cases. Principal morbidity was eclampsia $(40.8 \%)$ and fetal was prematurity $(36.4 \%)$. Maternal lethality was $11.1 \%$ and fetal mortality was $19.9 \%$ cases.

Conclusion: Severe preeclampsia is frequent in the UHCMC in N'Djamena. It is responsible for high maternal and fetal mortality. The practice of quality antenatal care, could prevent the occurrence of complications and improve the maternal-fetal prognosis.

\section{Introduction}

Severe preeclampsia is defined as high blood pressure $\geq 160$ $\mathrm{mm} \mathrm{Hg}$ for systolic and or $\geq 110 \mathrm{~mm} \mathrm{Hg}$ for diastolic associated with significant proteinuria $(5 \mathrm{~g} / 24 \mathrm{~h})$ occurring after 20 weeks of amenorrhea [1]. According to the World Health Organization, preeclampsia would be the third cause of maternal mortality after severe hemorrhages and infections [2]. Its incidence in the general population is around $7 \%$ to $10 \%$ [3].

\section{More Information}

*Address for Correspondence:

Foumsou Lhagadang, Associate Professor,

Faculty of Human Health Sciences, University of N’Djamena, Email: foumlhaga@gmail.com

Submitted: December 07, 2021

Approved: January 27, 2022

Published: January 28, 2022

How to cite this article: Foumsou L, Kouamé A, Danmadji NL, Gabkika BM, Damthéou S, et al. Severe preeclampsia at the University Hospital Center of Mother and Child (UHCMC) in N'djamena: Epidemiology and prognosis. Clin J Obstet Gynecol. 2022; 5: 009-012.

DOI: 10.29328/journal.cjog.1001099

Copyright License: @ 2022 Foumsou L, et al. This is an open access article distributed under the Creative Commons Attribution License, which permits unrestricted use, distribution, and reproduction in any medium, provided the original work is properly cited.

Keywords: Severe preeclampsia; Maternal morbidity and mortality; Stillbirth; UHCMC; N'Djamena

(4) Check for updates

(.) OPEN ACCESS
In Black Africa, its prevalence is higher and ranges from $4 \%$ to $18 \%$ [4]. The frequency of severe preeclampsia was $4.7 \%$ in Parakou University Hospital in Benin [5]. In Chad, Gabkika reports a prevalence of $1.74 \%$ in 2021 [6]. The high frequency of preeclampsia and the severity of its complications remains a public health problem. Its management is complex and constitutes a medico-obstetric emergency, its evolution is often unpredictable. The aim of this work was to improve the maternal and fetal prognosis of severe preeclampsia in the 
University Hospital Center of Mother and child (UHCMC) in N'Damena.

\section{Patients and method}

This was a prospective and descriptive survey covering three years period from January $1^{\text {st }}, 2017$ to December $31^{\text {st }}$, 2019 on the epidemiological and prognostic aspects of severe preeclampsia in the UHCMC in N'Djamena.

The study population consisted of pregnant women and parturient who were admitted in the maternity of the UHCMC during this study period. All pregnant women from 20 weeks of amenorrhea or parturient admitted for severe preeclampsia (BP 160/110 $\mathrm{mmHg}$, significant proteinuria $5 \mathrm{~g} / 24$ hours) or having developed severe preeclampsia during labor or in the post-partum and managed in the UHCMC of N'Djamena were included in the study. In our exercise where 24-hour proteinuria was difficult; we used the urinary strip. Proteinuria in the urinary strip greater than or equal to two crosses was considered significant. Any light preeclampsia, any pregnant woman or parturient admitted for gravidic hypertension; chronic hypertension during pregnancy, any severe preeclampsia managed in another structure referred or evacuated for complications and any parturient who refused to participate in this survey were not included in this study.

Studied variables were: age, educational level, profession, parity, mode of admission, number of prenatal care, gestational age, medical history, functional signs of severe preeclampsia, blood pressure, proteinuria, transaminases, creatinine, uricemia, diuresis, management, maternal and fetal morbidity, maternal and fetal lethality. The data collected was analyzed using SPSS 18.0 software.

\section{Results}

\section{Frequency}

We have recorded 406 pregnant women admitted for severe preeclampsia among 13,599 deliveries, giving a frequency of $2.98 \%$.

\section{Sociodemographic characteristics}

The most represented age group was 20 - 24 with $45.1 \%$. The mean age of patients was 23.27 years with extremes of 14 and 45 years (Table 1 ).

\section{Risk factors of severe preeclampsia}

Primiparity was the principal reported risk factor for severe preeclampsia with $61.3 \%$ of cases (Table 2 ).

\section{Antenatal care}

Patients did not practice antenatal care and represented $47.9 \%$ cases (Table 3 ).

\section{Functional signs}

The main functional signs were headaches (34\%), followed by blurred vision (9.8\%) and epigastric pain (9.6\%).

\section{Proteinuria with urinary strip}

Proteinuria was greater than three crosses in $83.7 \%$ cases and two crosses in $16.3 \%$.

\section{Management of severe preeclampsia}

Medical treatment was dominated by the use of magnesium sulphate in $98.3 \%$ cases. The antihypertensive most used was Nicardipine with $69.4 \%$ of cases. Blood transfusion was performed in $8.6 \%$ cases (Table 4 ).

\section{Mode of delivery}

Cesarean section was the most common mode of delivery with $52.4 \%$ cases versus $47.6 \%$ of low-pathway cases.

\begin{tabular}{|c|c|c|}
\hline Table 1: Distribution of patients according to Sociodemographic Characteristics. \\
\hline Variables & $\mathbf{n}$ & $\%$ \\
\hline Age (years) & & \\
\hline $15-19$ & 77 & 18.9 \\
\hline $20-24$ & 183 & 45.1 \\
\hline $25-29$ & 88 & 21.7 \\
\hline $30-34$ & 37 & 9.1 \\
\hline$\geq 35$ & 21 & 5.2 \\
\hline Total & 406 & 100 \\
\hline Parity & & 61.3 \\
\hline Primipara & 249 & 19 \\
\hline Paucipara & 77 & 19.7 \\
\hline Multipara & 80 & 100 \\
\hline Total & 406 & \\
\hline
\end{tabular}

Table 2: Distribution of patients depending on Risk Factors.

\begin{tabular}{|c|c|c|}
\hline Risk factors of severe preeclampsia & $\mathbf{n}$ & $\%$ \\
\hline Primiparity & 249 & 61.3 \\
\hline Multiple pregnancy & 22 & 5.2 \\
\hline Obesity & 3 & 0.7 \\
\hline Diabetes & 4 & 1 \\
\hline History of preeclampsia & 29 & 7.1 \\
\hline Personal history of high blood pressure & 18 & 4.4 \\
\hline Family history of high blood pressure & 37 & 9.1 \\
\hline
\end{tabular}

Table 3: Distribution of patients according to antenatal care.

\begin{tabular}{|c|c|c|}
\hline Antenatal care (ANC) & $\mathbf{n}$ & $\%$ \\
\hline 0 & 194 & 47.9 \\
\hline $1-3$ & 123 & 30.2 \\
\hline$\geq 4$ & 89 & 21.9 \\
\hline Total & 406 & 100 \\
\hline
\end{tabular}

Table 4: Distribution of patients under management of severe preeclampsia.

\begin{tabular}{|c|c|c|}
\hline Management instituted & $\mathbf{n}$ & $\%$ \\
\hline Magnesium sulphate & 399 & 98.3 \\
\hline Nicardipine & 282 & 69.4 \\
\hline Methyldopa & 119 & 29.3 \\
\hline Betamethasone/Dexamethasone & 74 & 18.2 \\
\hline Furosemide & 26 & 6.4 \\
\hline Total blood transfusion & 35 & 8.6 \\
\hline Fresh plasma transfusion & 12 & 3.0 \\
\hline Dialysis & 7 & 1.7 \\
\hline
\end{tabular}




\section{Maternal morbidity and lethality}

Maternal morbidities were dominated by eclampsia with $40.8 \%$ of cases. We recorded 21 maternal deaths or maternal lethality of $5.1 \%$ (Table 5).

\section{Fetal morbidities}

Prematurity was the most reported fetal morbidity with $36.4 \%$ of cases, followed by intrauterine death $(15.9 \%)$ and perinatal asphyxia (3.7\%).

Table 5: Distribution of patients according to maternal morbidities.

\begin{tabular}{|c|c|c|}
\hline Maternal morbidities & $\mathbf{n}$ & $\%$ \\
\hline Eclampsia & 166 & 40,8 \\
\hline Abruptio placentae & 16 & 3,9 \\
\hline Anemia & 15 & 3,7 \\
\hline HELLP syndrome & 13 & 3,2 \\
\hline Pulmonary edema & 11 & 2,7 \\
\hline acute renal failure & 15 & 3,7 \\
\hline
\end{tabular}

\section{Discussion}

The frequency of severe preeclampsia in this survey was 2.98\%. This result is similar to that of Tchente, et al. [7] in Cameroon in 2015 and Tchaou, et al. [8] in Benin, in 2013, who reported respectively $2.3 \%$ and $2.46 \%$ of cases. However, it is lower than those of Aguemon, et al. [9] in 2017 in Benin and Rajni, et al. [10] in 2020 in India who respectively obtain $4.8 \%$ and $7 \%$ severe preeclampsia. This low frequency could be explained by the fact that some cases of severe preeclampsia were not diagnosed during pregnancy due to lack of antenatal care deliveries at home and referred for management of complications and ignorance of the danger signs of severe preeclampsia.

The mean age of patients was 23.27 years \pm 1.3 year with extremes of 14 and 45 years. Tchente, et al. [7] report an average age of 31.4 years. This difference in mean age would be explained by the socio-cultural context specific to each country, such as early marriage, the low level of schooling of women.

Regarding parity, primipara predominated with $61.3 \%$. This observation was made by Rajni, et al. [10] and Obossou, et al. [5] who found a predominance of primiparas of $53.57 \%$ and $40.9 \%$ respectively. This result is consistent with literature data that consider primiparity as one of the most important risk factors of preeclampsia $[7,9,11]$.

Good-quality antenatal cares are capital for screening and early management of pathologies that may involve the maternal-fetal prognosis. Therefore, WHO currently recommends eight antenatal care during pregnancy. In this series, absence of prenatal follow-up was noted in $47.9 \%$ of cases. This result is comparable to those of Keita, et al. [12] in 2016 in Mali and Gabkika, et al. [6] in Chad in 2021 who reported $49 \%$ and $50.8 \%$ of cases respectively. This high rate reported in this series would be related to the low level of education of women who do not have a good knowledge of the benefits and interests of antenatal care and precarious economic situation which does not allow them to obtain quality medical care.

From a therapeutic point of view, $98.3 \%$ of patients had received anticonvulsant treatment based on magnesium sulphate. This number is found in the range of other series $[3,13,14]$ who used anticonvulsant magnesium sulphate for the management of severe preeclampsia in the order of $94 \%$ and $100 \%$. This therapeutic attitude is consistent with the recommendations of WHO for the management of severe preeclampsia and eclampsia. This drug would provide more benefit in the maternal-fetal prognosis than other anticonvulsants. According to Duley, et al. [13], Girardm, et al. [14], magnesium sulphate would lead to a significant improvement in maternal and fetal prognosis in terms of maternal and fetal morbidity and mortality compared to diazepam. Nicardipine was the antihypertensive most associated with magnesium sulphate with $69.4 \%$ of cases. This figure is identical to that of Tchente, [7] who uses Nicardipine as an antihypertensive in $68 \%$ of cases.

Obstetric management consists in the termination of the pregnancy. The difficulty is to determine the moment of termination of pregnancy. For this, the decision must consider the term of the pregnancy and especially the maternal and/or fetal clinical state.

Concerning obstetric management, cesarean section was the most used mode of delivery with $52.4 \%$ of cases. Other authors such as Tchentem, et al. [7] and Ahmed, et al. [15] found $57.5 \%$ and $47.3 \%$ respectively of the cases of cesarean section. This high number of cesarean sections in this study might have resulted from delayed diagnosis in peripheral structures and the late references of patients to the practitioner to perform a cesarean section of maternal-fetal rescue.

\section{Prognosis aspects}

The maternal complications found are comparable to those described in the literature. We reported $54.3 \%$ of maternal complications due to severe preeclampsia. This result is found in the range of data from other African authors $[7,9,10$, 16 which is around $43.2 \%$ to $62 \%$. This could be explained by the delayed diagnosis of result from the absence or poor antenatal care and the reluctance of the parents to give their agreements for the cesarean section, thus causing a delay in the management.

Eclampsia was the principal maternal complication of severe preeclampsia with $40.8 \%$ of cases. According to Foumsou, et al. [17] in 2014 in N'Djamena, Chad, preeclampsia and its complications were the second cause of maternal death after hemorrhages. We reported maternal lethality of $5.4 \%$. This result is higher than those of some authors such 
as Ahmed, et al. [15], Aguemon, et al. [9], Neha, et al. [16], as well as Rakotomalala, et al. [18] in 2016 in Madagascar who respectively obtained $1.25 \%, 2.4 \%, 2.6 \%$ and $3.03 \%$ maternal lethality. The delayed diagnosis, the quality of management, especially the insufficiency of the technical plateau and the refusal of the family for surgery would explain this high rate of maternal lethality.

As for fetal morbidity, the study found that prematurity was the most represented fetal complication with $36.4 \%$ of cases. This result is superimposed on that of Rakotomalala, et al. [18] who noted $35.07 \%$ of premature cases. This figure is lower than those of Tchente, et al. [7] and Rajni et al. [10] which were respectively $42.8 \%$ and $53.6 \%$ premature cases. This prematurity is essentially iatrogenic in the context of maternal and/or fetal rescue due to maternal and fetal complications of severe preeclampsia. We recorded 19.9\% of fetal mortality. This result is close to that of Ahmed, et al. [15] who reported $16.65 \%$ fetal mortality. Neha, et al. [16] reported $30 \%$ of fetal mortality. This high fetal mortality in our regions is mainly due to prematurity, acute fetal asphyxia and the inadequacy of technical trays in neonatology.

\section{Conclusion}

Severe preeclampsia is a frequent pathology in the University Hospital Centre of Mother and Child in N'Djamena. It is frequent on young housewives, primipara patients, without antenatal care. Medical management was based on the administration of magnesium sulphate associated with antihypertensives. The mode of delivery was dominated by the cesarean section. The most reported complications were eclampsia for the mother and prematurity for the newborn. It was responsible for high maternal and fetal mortality. The prevention of severe preeclampsia requires quality antenatal care in which high blood pressure in pregnancy is diagnosed and adequately managed. On the other hand, good monitoring of the labor of delivery is necessary.

\section{References}

1. American College of Obstetricians and Gynecologists, Committee in practice Obstetrics. Gestational Hypertension and Preeclampsia. Pract Bull. 2019; 133: e1-e25. PubMed: https://pubmed.ncbi.nlm.nih. gov/30575675/

2. World Health Organization. Recommendations for the Prevention and Treatment of Pre-eclampsia and Eclampsia. WHO. 2014; 39. www.who.int/reproductivehealth/publications/maternal_perinatal_ health/9789241548335/en/index.html

3. French College of Gynecologists and Obstetricians (NCFGO) and French Anesthesia and Reanimation Society. Formalized
Expert Recommendations. Management of the patient with severe preeclampsia. NCFGO. 2020; 38.

4. Cissé CT, Thiam M, Diagne PM, Moreau JC. Pre-eclampsia in the African environment: epidemiology and prognosis in University Hospital of Dakar. Letter of Gynecologist. 2005; 301: 8-13.

5. Obosou AAA, Salifou K, Hounkapatin B, Hounkponou F, Quenum CT, et al. Epidemiological and prognostic aspects of severe preeclampsia at the maternity in Borgou Departmental Hospital of Parakou (Benin). Parakou University. Ann Health Sci Series. 2012; 2: 1-3.

6. Madoué GB, Lhagadang F, Silé SN, Dorenavant D. Management of Severe Preeclampsia Before Term in N'Djamena Mother and Child University Hospital. J Gynaecol Womens Healthcare. 2021; 3: 5.

7. Tchente NC, Belley PE, Halle EG, Fofack TLJ, Nana NT, et al. Complications and management of preeclampsia and eclampsia in Douala general hospital. Rev Med Pharm. 2015; 5: 483-490.

8. Tchaou BA, Tshabu-aguemon TC, Hounkponou NFM, Adisso S, Aguemon AR, et al. Severity and prognosis of patients treated for severe preeclampsia Parakou Departmental University Hospital (Benin). Black Afr Med. 2013; 489-495.

9. Tshabu-aguemon TC, Ogourindé MO, Megnissé SH, Lokossou S, Bejamin $\mathrm{H}$, et al. Prognostic factors of severe preeclampsia in University Maternity Hospital of Porto-Novo in Benin. J Soc Biol Benin. 2017; 27: 59-64.

10. Rajni P, Chitra S. Maternal and perinatal outcome of severe preeclampsia and eclampsia. JMSCR. 2020; 8: 242-245.

11. Mervielle P, Dumont A, Bonnardot J, PerierJF, Rondeau E, et al Severe pre-eclampsia: management, conservative treatment justified? J Gynaecol Obstet Biol Reprod. 2014; 26: 238-249. PubMed: https://pubmed.ncbi.nlm.nih.gov/9265044/

12. Keita M, Diallo B, Samaké B, Foumba S, Dicko H, et al. Epidemiology and maternal prognosis of eclampsia in reanimation service in the Bamako G-Point University Hospital University. Med Mali. 2016; 31: 1-9. PubMed: https://pubmed.ncbi.nlm.nih.gov/30079675/

13. Duley L, Henderson-Smart DJ, Walker GJ, Chou D. Magnesium sulfate versus diazepam for eclampsia. Cochrane Database Syst Rev. 2010; 2010: CD000127.

PubMed: https://pubmed.ncbi.nlm.nih.gov/21154341/

14. Girard B, Beucher G, Muris C, Simonet T, Dreyfus M. Magnesium sulphate and severe pre-eclampsia: safety in common practice in targeted indications. J Gynecol Obstet Biol Repord. 2005; 34: 17-22. PubMed: https://pubmed.ncbi.nlm.nih.gov/15767913/

15. Ahmed TB, Youness B, Sakher M, Naima S. Epidemiology of preeclampsia in Casablanca. PAMJ. 2020; 12: 112-119.

16. Saxena N, Bava AK, Nandanwar Y. Maternal and perinatal outcome in severe preeclampsia and eclampsia. Int J Reprod Contracept Obstet Gynecol. 2016; 5: 2171-2176.

17. Foumsou L, Saleh A, Kaimba O. The determinants of maternal mortality in N'Djamena National Reference General Hospital in Chad. Chad Scientific Rev. 2014; 1: 35-41.

18. Rakotomalala Z, Randriambololona DMA, Andriampanarivo HM, Rakotozanany B, Randriamaromanana ZN, et al. Poor prognosis factors of pre-eclampsia in Madagascar. Trop Health Med. 2016; 26: 78-82. 